DOI 10.5216/ag.v4i9.9223

\title{
AVÁ-CANOEIRO: guardiões do Cerrado do Norte Goiano
}

\section{AVÁ-CANOEIRO: guardians of the North Goiano Cerrado}

\section{AVÁ-CANOEIRO: les tuteurs du Cerrado Goiano Nord}

\author{
Lorranne Gomes da Silva \\ Mestranda do curso de Geografia pela Universidade Federal de Goiás - Instituto de Estudos Sócio- \\ Ambientais (IESA). \\ Rua Ary Bento Xavier Qd: 04 Lt: 12 - Setor: Panorama Parque \\ Inhumas-Goiás CEP: 75400-000 \\ lorrannegomes@gmail.com
}

\section{Resumo}

O objetivo deste artigo é apresentar como o grupo indígena Avá-Canoeiro está inserido no contexto do Cerrado do norte goiano e a importância de sua reserva - 38 mil hectares - tornando assim os "Guardiões do Cerrado". Ao considerar que o uso e a ocupação do Cerrado pela modernização do capital se deram em tempos, espaços distintos e heterogêneos, a região norte é a grande detentora da biodiversidade. Os povos indígenas de Goiás apresentam saberes e modalidades de uso de espécies do bioma que não comprometem a sua redução, tal como têm sido as atividades econômicas capitalistas. No caso específico dos Avá-canoeiro, além de sua cultura ecológica não ser de acumulação, a vastidão de sua terra, contrastando com a sua diminuta população, são fatores de preservação da biodiversidade. Os Avá-Canoeiro teriam 38 mil hectares se estivessem localizados no sul ou sudoeste goiano? Para esta pesquisa foram utilizados levantamentos bibliográficos e trabalhos de campo ${ }^{1}$. Os resultados baseiam-se em dois fatores - o da cultura ecológica dos Avá-Canoeiro junto com a posição do norte - são elementos que protegem a biodiversidade, mas não acabam com outros níveis de pressão, como é a participação do hidronegócio e de atividades minero-extrativistas.

Palavras-chave: Avá-Canoeiro, cerrado goiano, guardiões do cerrado

$1 \quad$ Alguns trabalhos de campo foram financiados pelo projeto BIOTEC (Biotecnologias e Biodiversidade Gestão Participativa no Cerrado Brasileiro) - Realizado pela Universidade Federal de Goiás, desenvolvido no Instituto de Estudos Sócio-ambientais (IESA) em parceria com o Institut de Recherche pour le Develóppement (IRD) da França. 


\begin{abstract}
The objective of this article is to present how the indigenous group Avá-Canoeiro is inserted in the Northern Goias Cerrado and the importance of their territory, an area of 38,000 hectares, what makes them the "Guardians of the Cerrado". Taking into account that the use and occupation of the Cerrado occurred through the modernization of the capital within distinct and heterogeneous time and space, the northern region has been a great holder of biodiversity. The indigenous peoples have knowledge and methods of use of the biome that do not compromise its natural assets in contrast to the capitalist economic activities. In the specific case of Avá-Canoeiro, they have an ecological culture and perception of non-accumulation; this fact, combined with the vastness of their land and small population, contributes to the preservation of the biodiversity. Would the Avá-Canoeiro have 38,000 hectares if their land was located in the southern or southwest part of Goias? For this investigation, literature review and field work were done. The results were based on two factors: first, the ecological culture of the AváCanoeiro; second, the fact that their territory is situated in the northern part of Goias. These two aspects contribute for the protection of the biodiversity, but they do not ward off it from other impacting activities such as the hydro business and mining.
\end{abstract}

Key Words: Avá-Canoeiro, northern Goias cerrado, guardians of the cerrado

\title{
Résumé
}

L'objectif de cet article est présenter comme le groupe Indigène Avá-Canoeiro est inséré dans le contexte de l'Enclos Cerrado du nord goiano et l'importance de sa réserve - 38 hectares - en devenant ainsi les "Les tuteurs du cerrado". À l'examen que l'utilisation et l'occupation du Cerrado par la modernisation du capital se sont données dans des temps, espaces distincts et hétérogènes, la région norde est la grande détenteuse de la biodiversité. Les peuples indigènes de Goiás présentent des savoirs et des modalités d'utilisation d'espèces de la bioma qui ne compromettent pas leur réduction, telle que cela a été les activités économiques capitalistes. Dans le cas spécifique de Avá-canoeiro, outre sa culture écologique ne pas être d'accumulation, l'ampleur de sa terres, en contrastant avec sa amoindrie population, sont des facteurs de conservation de la biodiversité. Avá-Canoeiro auraient 38 mille hectares s'étaient localisés dans le sud ou la sud-ouest goiano ?Pour cette recherche ont été utilisés des enquêtes bibliographiques et des travaux de champ. Les résultats se basent sur les deux facteurs - la de la culture écologique de Avá-Canoeiro conjointement position du nord - sont des éléments ils lesquels protègent la biodiversité, mais ne finissent pas avec autres niveaux de pression, comme c'est la participation de la hidronegócio et des activités minero-extrativistas.

Mots clés: Avá-Canoeiro - Cerrado Goiás - Les tuteurs du cerrado

\section{Considerações Iniciais}

Os dados demográficos da população indígena atual no Brasil transitam entre 350.000 a 550.000 indígenas. Na área contínua do Cerrado dos chapadões centrais do 
Brasil, a população encontra-se em torno de 44.000 e 45.118 habitantes Barbosa (2008, p. 80) distribuídos em terras do Maranhão, do Tocantins, de Goiás, do Leste de Mato Grosso e do Mato Grosso do Sul. Na atualidade Barbosa (2008) aponta que há 26 povos indígenas que vivem na área continua do Cerrado.

No Estado de Goiás de acordo com a FUNAI (2004) existiam 21 grupos Indígenas no início da formação do antigo território da Capitania de Goiás. Esses grupos espalhavam-se desde o sul da capitania no Rio Paraná, hoje Mato grosso do Sul, até no extremo norte da capitania, atual microrregião do Bico do Papagaio, no estado do Tocantins.

Goiás foi formado sobre territórios dos povos Indígenas como: os Goyá, Krixá, Kayapó, Xavante, Araés, Canoeiro, Apinajá, Capepuxi, Temimbó, Amadu, Xerente, Tapirapé, Poxeti, Karajá, Gradaú, Tecemedu, Guiaguçu, Porecramecrã, Curemecrá que aqui habitavam antes da chegada dos colonizadores. Esses povos deslocavam-se dentro de um espaço cujo povoamento regular era feito por povos aparentados. Teixeira Neto (2002, p.38) afirma que:

O espaço inicial, ocupado por tribos indígenas, foi apenas o esboço que serviu de base para, mais tarde, se institucionalizar o território da Capitania, depois Província e Estado de Goiás. Por si só já dividido, segundo a distribuição geográfica daquelas tribos, esse espaço, agora institucionalizado, perdeu a solidariedade de que necessitava para manter-se coeso.

Tendo seus territórios usurpados, recortados ou invadidos, muitos povos indígenas desapareceram. Outros ficaram impedidos de desenvolver suas atividades de subsistência material e reprodução social nos moldes tradicionais e passaram por um processo que envolve diferentes formas de adaptação sócio-ecológicas com perdas de difícil mensuração, já que cada uma dessas sociedades define e utiliza de forma singular seu meio ambiente.

Atualmente, vivem no Cerrado Goiano apenas três etnias: os Tapuios do Carretão em Rubiataba; os Karajá em Aruanã e os Avá-Canoeiro em Minaçu/Colinas do Sul, sujeitos escolhidos para essa discussão.

A escolha dos Avá-Canoeiro como sujeitos desse estudo, deu-se pelas questões peculiares que envolvem esse grupo. Entre eles: a localização no norte goiano 
garantindo uma Terra Indígena de 38.000 hectares - Uma área de proteção do Cerrado; o diminuto contingente populacional que não mantém uma cultura ecológica de acumulação.

Busca-se ao longo do texto refletir e compreender porque considerar os AváCanoeiro como "Guardiões do Cerrado do norte goiano".

\section{O Povo Indígena Avá-Canoeiro: Uma História de Resistência}

O povo Avá-Canoeiro tem uma língua própria, pertencente à família TupiGuarani, do tronco linguístico Tupi. Em relação aos povos Tupi-guarani, os AváCanoeiro são mais próximos linguisticamente dos Tupi originários do baixo TocantinsAraguaia, como os Suruí, os Parakanã, os Assurini do Tocantins, os Amanayé, os Guajajara e, especialmente, os Tapirapé.

É uma língua altamente ameaçada de extinção, devido ao reduzido número de falantes, e praticamente sem documentação disponível e estudos feitos. Borges (2002, p. 24): "Os estudos realizados sobre essa língua indígena brasileira são raros e os poucos que há limitam-se a descrever alguns aspectos fonético-fonológicos ou a apresentar algumas listas de palavras".

O nome "Avá-Canoeiro" para designar essa etnia, foi consolidado a partir da década de 1970 considerando os registros feitos por pesquisadores, indigenistas e funcionários da FUNAI (Fundação Nacional do Índio) e Furnas Centrais Elétricas S.A que com eles mantinham contato.

Apropriaram-se do termo "awa" que na língua Avá-Canoeiro como em outras línguas tupi-guarani, significa gente, pessoa, ser humano, homem adulto. O cognome “canoeiro" deve-se à habilidade para navegar canoas e ubás ${ }^{2}$ pelas correntezas dos rios. De acordo com Silva (2005, p.16): “Os Avá-Canoeiro auto-designam-se awa 'gente', em oposição a maira "não-indígena"”.

Somente a partir da década de 1970 partes de grupos dos Avá-Canoeiro passaram a ter contato permanente com não-índios. Em 1820 esse povo começou ser

\footnotetext{
2 Tipo de canoa usada entre povos indígenas brasileiros, talhada em casca de árvore ou escavada a fogo.
} 
encontrado nas altas montanhas que ficam entre o rio Maranhão e os povoados de Santa Tereza e Amaro Leite; em algumas aldeias no rio Canabrava entre outros lugares do estado de Goiás e Tocantins.

A localização dos Avá-Canoeiro era crucial na ocupação do território goiano já que situava-se em plena área de expansão da pecuária e em meio à rota de contato (o rio Tocantins) que ligava as duas mais importantes regiões de desenvolvimento - a capital da província e Porto Real, hoje Porto Nacional. Um grupo permaneceu no estado de Goiás perambulando entre as montanhas escarpadas e de difícil acesso da região norte.

De acordo com Rivet (1924, p. 175):

Como reação aos conflitos cada vez mais violentos, alguns grupos AváCanoeiro iniciaram, entre 1844 e 1865, um processo de deslocamento em direção ao Araguaia Até o término do século, já tinham atingido as proximidades da Ilha do Bananal.

No início do século XX, os Avá-Canoeiro distribuíam-se em uma extensa área desde os sopés da Serra Dourada até o interior da Ilha do Bananal. Moura (2006, p. 122) afirma que: "Antes da colonização do Brasil Central, os Avá deveriam ter aldeias com população não muito grande, possivelmente de 250 a 300 habitantes".

A capacidade de adaptação foi à maior arma de sobrevivência, já que, desde o início do século XIX, a ocupação de seu território tradicional por fazendas, garimpos, vilas e cidades obrigou os Avá-Canoeiro a deslocamentos contínuos para se manterem vivos. Silva (2005, p. 14), afirma que:

Os Avá-Canoeiro foram reduzidos drasticamente por séculos de conflitos, massacres e expulsões territoriais de seus domínios no Brasil Central que culminaram na fragmentação de suas aldeias em pequenos grupos como meio de sobrevivência.

Atualmente, os Avá-Canoeiro estão divididos em duas famílias: uma habitando a bacia do Rio Araguaia, no Estado de Tocantins, e outra habitando a bacia do Rio Tocantins, no Estado de Goiás como mostra a figura 01: 

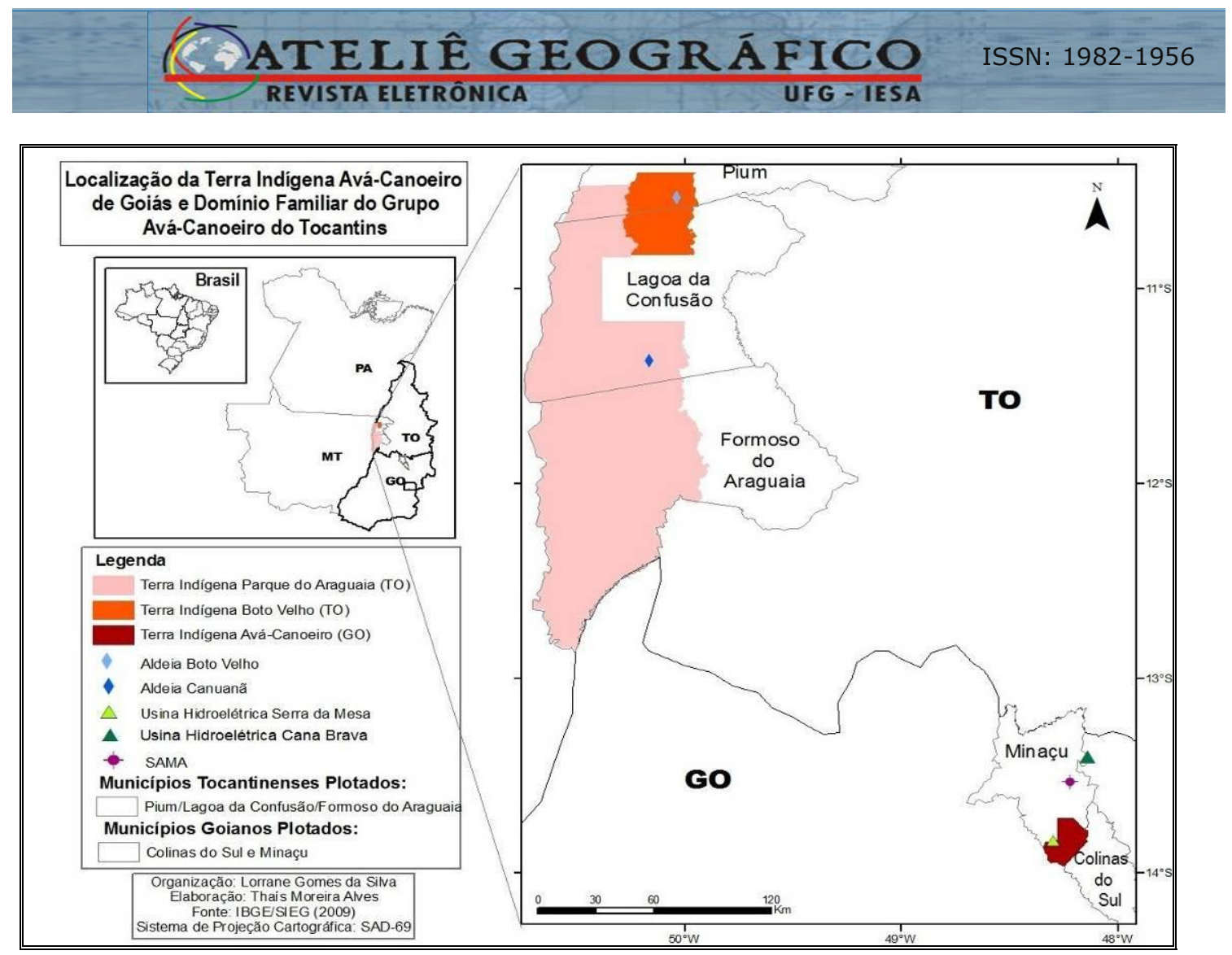

Figura 01 - Mapa de Localização das famílias Avá-Canoeiro de Goiás e Tocantins

De acordo com o mapa 01, a família do Araguaia encontra-se dispersa em duas aldeias na Ilha do Bananal no interior da Terra Indígena dos Javaé no Parque do Araguaia: Aldeia Canuanã, próxima ao município de Formoso do Araguaia, e Aldeia Boto Velho, a $60 \mathrm{~km}$ da Lagoa da Confusão, enquanto a família de Goiás está em terra própria entre os municípios de Minaçu e Colinas do Sul.

O Parque do Araguaia é vinculado ao IBAMA $^{3}$ e fica ao norte da Ilha do Bananal. Essa região possui ampla rede de drenagem formada por rios de médio a grande porte, riachos, nascentes, ipucas ${ }^{4}$ e vários lagos.

Os solos dessa região variam entre ácidos com baixa fertilidade natural e solos profundos, com vegetação típica de floresta e Cerrado. A vegetação se compõe de várias paisagens como: cerradão, mata seca e inundada, extensos campos inundados, vegetação de encostas secas e de bancos de areia.

A Ilha do Bananal pode ser descrita, em termos ambientais, como uma área de transição entre o Cerrado e o domínio Amazônico. Para um povo indígena que pode ser descrito como caçador e coletor, como os Avá-Canoeiro do Araguaia, a área é

\footnotetext{
${ }^{3}$ Instituto Brasileiro de Meio-Ambiente.
} 
excepcionalmente propícia, uma vez que lhes oferece os recursos de caça e coleta apesar de não terem uma terra própria.

Separados há mais de um século, os Avá-Canoeiro do Tocantins e do Araguaia desenvolveram histórias distintas e diferenças culturais consideráveis (Borges, 2002). Em 1988, a FUNAI tentou promover a união dos grupos, mas fracassou devido à falta de recursos e ao isolamento do Posto Indígena Avá-Canoeiro, se comparado à movimentada aldeia de Canuanã onde vive a família do Araguaia.

A família do Araguaia convive com outras etnias como os Tapirapé, Javaé e promovem casamentos interetnicos ${ }^{5}$ aumentando assim o número de pessoas. Já a família do Tocantins composta por seis pessoas, quase não mantém contato com outras etnias, dificultando a possibilidade de casamento já que são apenas dois jovens na família.

Existem 14 índios Avá-Canoeiro ${ }^{6}$ de acordo com Toral (1984/1985) e estima-se que haja pessoas ainda sem contato permanente.

Entre os índios já contatados pela FUNAI, os grupos do Araguaia e Tocantins apresentam as seguintes características, como mostra o quadro I:

Quadro I: Algumas características do povo Avá-Canoeiro

\begin{tabular}{|c|l|c|c|}
\hline GRUPO & \multicolumn{1}{|c|}{ NOME } & $\begin{array}{c}\text { IDADE } \\
\text { APROXIMADA }\end{array}$ & SEXO \\
\hline $\begin{array}{c}\text { Ilha do Bananal - } \\
\text { Tocantins }\end{array}$ & 1-Tutau & 68 & Masculino \\
\hline & 2-Makakira & 48 & Feminino \\
\hline & 3-Agadmi & 45 & Masculino \\
\hline & 4-Txiele & 20 & Feminino \\
\hline & 5-Davi & Menos de 15 & Feminino \\
\hline & 6-Sirlene & Menos de 15 & Feminino \\
\hline & 7-Brena & Menos de 15 & Masculino \\
\hline
\end{tabular}

\footnotetext{
${ }^{4}$ Trecho onde a água, após a enchente do rio, ficou por um tempo estagnado.

${ }^{5}$ Casamentos entre etnias diferentes.

${ }^{6}$ Sem considerar os casamentos interetnicos, apenas os Avá-Canoeiro.
} 


\begin{tabular}{|l|l|c|l|}
\hline $\begin{array}{l}\text { Município de } \\
\text { Minaçu - Goiás }\end{array}$ & 1-Matxa & 70 & Feminino \\
\hline & 2-Nakwatxa & 65 & Feminino \\
\hline & 3-Tuia & 37 & Feminino \\
\hline & 4-Niwatima & 19 & Feminino \\
\hline & 5-Iawi & 48 & Masculino \\
\hline & 6-Jatúlika & 22 & Masculino \\
\hline
\end{tabular}

Elaboração: SILVA, Lorranne Gomes da

Fonte: Trabalho de campo, março, 2009 e Toral (1984/1985)

As duas famílias quase não se encontram devido à distância e também porque a família de Goiás não aceitou permanecer na Ilha do Bananal e nem a do Tocantins quis ficar em Goiás. Dessa forma, o contato entre as duas famílias são cada vez mais raros.

\section{Onde está o Território Avá-Canoeiro em Goiás?}

A Terra Indígena Avá-Canoeiro está situada precisamente nos municípios de Minaçu e Colinas do Sul - no extremo norte do Estado de Goiás, pertencendo à mesorregião do Norte goiano e a microrregião de Porangatu -, a 510 km de Goiânia e $445 \mathrm{~km}$ de Brasília, como mostra a figura 02: 

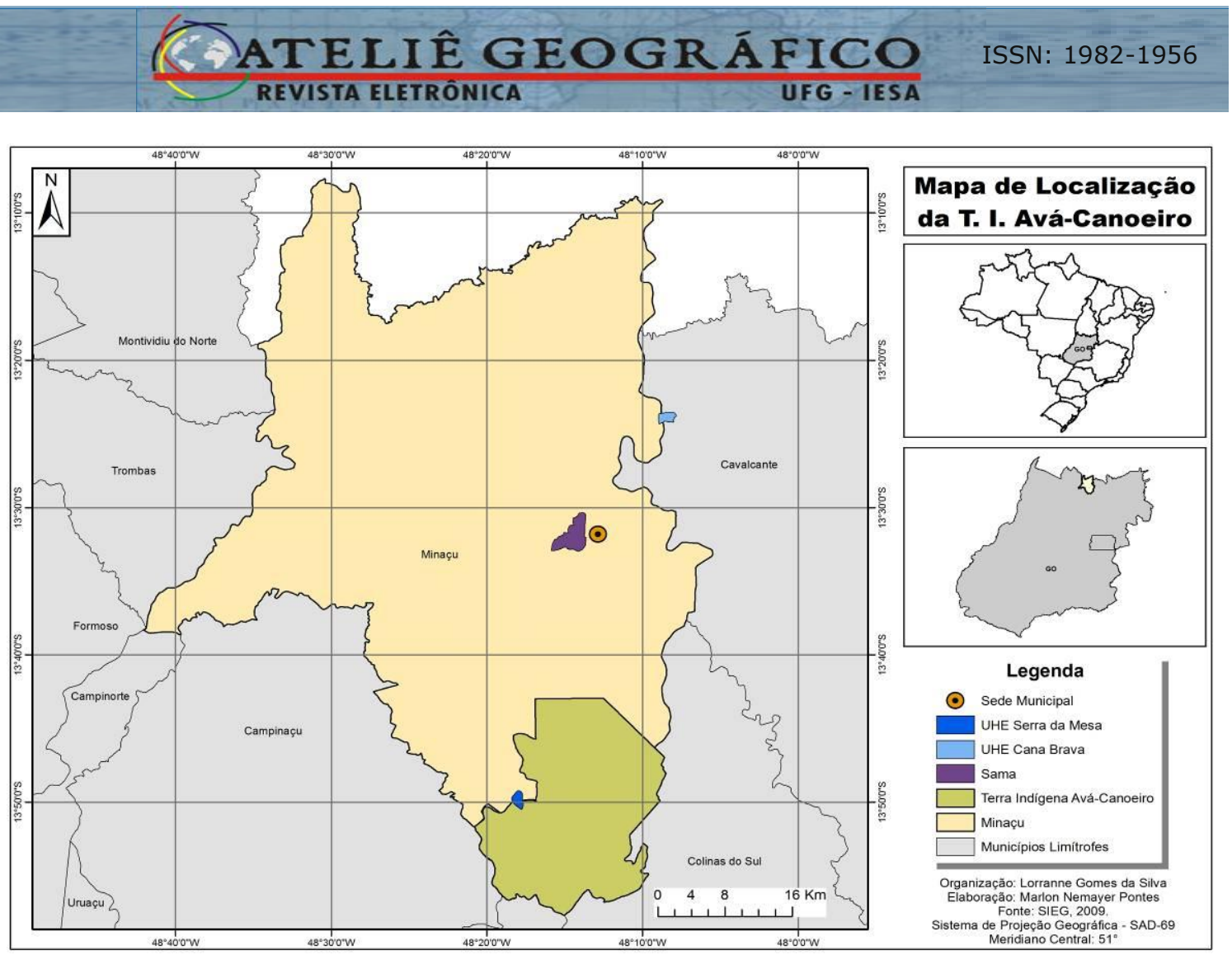

Figura 02- Mapa de Localização da Terra Indígena Avá-Canoeiro

Historicamente, a origem da economia goiana está ligada à mineração, e as cidades da mesorregião do norte de Goiás não fogem da regra. A origem de Minaçu e a mineração se confundem. Com o diferencial de que Minaçu não foi o ouro o responsável pela sua origem e posterior desenvolvimento econômico; mas a descoberta de um material não metálico: o amianto crisotila, como mostra a figura 03:

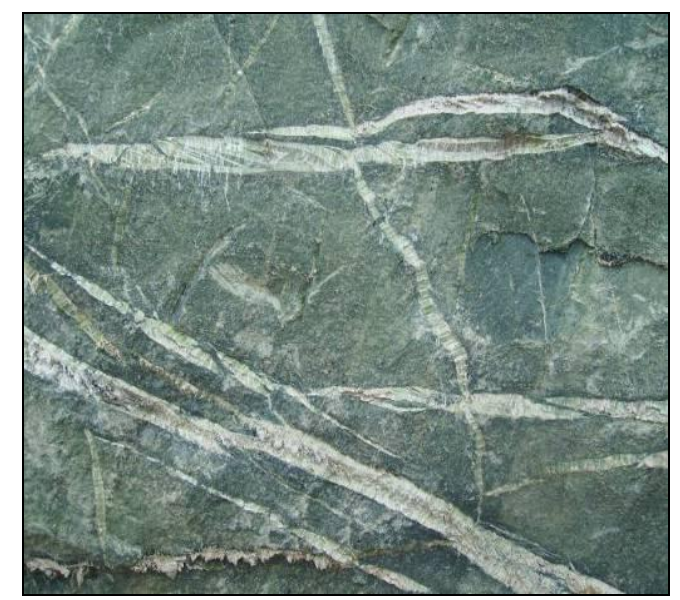

Figura 03 - Amianto crisotila

Autora: SILVA, Lorranne Gomes da 
As atividades da $\mathrm{SAMA}^{7}$ atraíram muitas outras atividades econômicas para a cidade, nas áreas da prestação de serviços, comércio e indústria. A própria implantação de infra-estrutura, como a construção da vila industrial dotado de estação de tratamento de água e esgoto, centro educacional, centro de formação e treinamento profissional, hospital, clube social, centro esportivo e de lazer demandou uma ampla prestação de serviços, e a mão de obra de muitos operários.

Atualmente a SAMA não emprega tantas pessoas como em anos anteriores, devido à modernização da produção, fato presente na nova economia capitalista. $\mathrm{Na}$ economia do município a mineradora possui papel essencial, atuando na área de produção e exportação de amianto crisotila e é responsável pela maior parte da arrecadação de $\mathrm{ICMS}^{8}$.

As implantações das Usinas Hidrelétricas de Serra da Mesa e de Cana Brava contribuíram também economicamente para o crescimento da cidade de Minaçu, com a arrecadação de ICMS e ISSQN ${ }^{9}$.

Especialmente no período de construção da UHE de Serra da Mesa (1986-1998), houve uma expansão do comércio local. Nesse período destaca-se: abertura de muitos estabelecimentos comerciais; crescimento do mercado imobiliário e surgimento de bairros novos devido ao grande crescimento demográfico. Dentre os bairros estão: a vila Popular, vila Manchester e vila de Furnas, construída pela empresa Camargo Correia para abrigar os construtores (engenheiros e operários) da UHE de Serra da Mesa.

A SAMA, as Usinas Hidrelétricas de Serra da Mesa e Cana Brava aos poucos foi reconfigurando o município de Minaçu que vem crescendo a cada dia. Há 26 quilômetros de Minaçu está a Terra Indígena Avá- Canoeiro ${ }^{10}$. A construção das Usinas Hidrelétricas de Serra da Mesa e Cana Brava com a formação do lago não limitaram

\footnotetext{
${ }^{7}$ Mineradora de Amianto.

${ }^{8}$ Imposto sobre circulação de mercadorias e serviços.

${ }^{9}$ Imposto sobre serviços de qualquer natureza.

${ }^{10}$ Parte em estrada de terra, passando por entre morros, atravessando fazendas de gado e campos de Cerrado.
} 
apenas em invadir partes de vários municípios do norte, como também 10\% da Terra Indígena $^{11}$.

A área da Terra Indígena Avá-Canoeiro que ainda encontra-se em processo de homologação ${ }^{12}$, é de 38 mil hectares ao longo do córrego Pirapitinga, na margem esquerda do rio Tocantins, a $14 \mathrm{~km}$ à jusante da Usina de Serra da Mesa (administrada por FURNAS Centrais Elétricas) e a $10 \mathrm{~km}$ da Usina Hidrelétrica de Cana Brava (administrada pelo grupo Tractebel Suez).

Atualmente vivem na Terra Indígena Avá-Canoeiro, seis pessoas nas quais estabeleceram ao longo do tempo uma relação de confiança ${ }^{13}$ por estarem juntas fugindo das perseguições e ainda recompondo suas vidas: Matxa, Nakwatxa, Iawi, Tuia e os filhos desta com Iawi: Jatulika e Niwatima. Como mostra a figura 04:

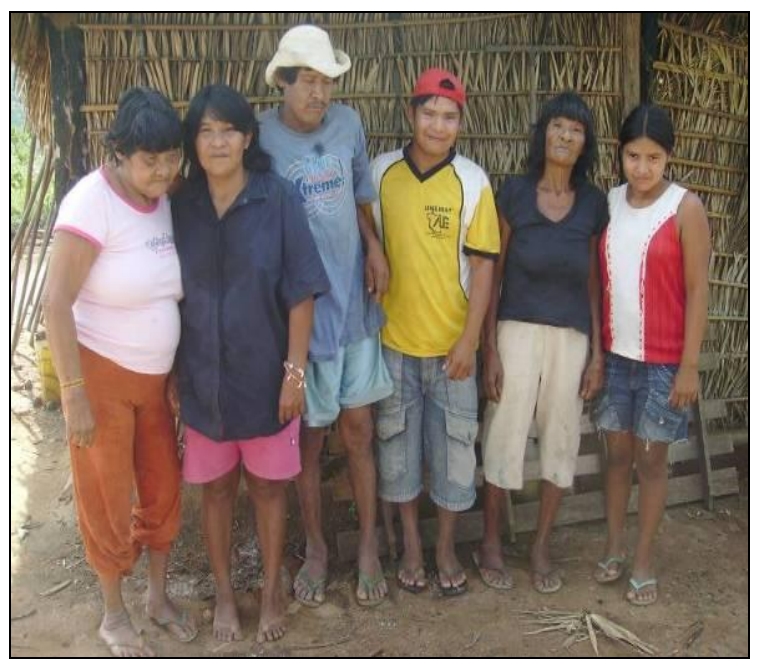

Figura 04: Índios da Tribo Ava-Canoeiro- - Da direita para esquerda: Niwatima; Nakwatxa; Jatulika; Iawi; Tuia e Matxa

Autora: SILVA, Lorranne Gomes

\footnotetext{
11 A Usina de Cana Brava foi uma construção integrada à Usina de Serra da Mesa no aproveitamento hidroelétrico de São Félix, ligado ao sistema integrado da região sudeste. O que invadiu a Terra Indígena não foram as Usinas propriamente ditas, mas o lago que se formou na junção dos dois empreendimentos. 12 Cabe ao presidente da República a homologação da Terra indígena. Após a homologação, o registro das terras deve ser efetuado em 30 dias no cartório de imóveis da comarca onde se localizam as terras e no SPU (Serviço de Patrimônio da União).

${ }^{13}$ Viveram muito tempo fugindo, assistindo massacres de sua família, por motivo de proteção vivem todo tempo juntos. A convivência deles é boa, com poucos conflitos internos. Cada um faz o que gosta no decorrer do dia e a noite todos ficam reunidos. Matxa apesar de ser a mais velha e ser considerada a matriarca do grupo, encontra-se debilitada fisicamente, ficou cega devido um glaucoma e pouco sai da oca. Iawi e Nakwatxa assumiram o exercício da caça, da pesca e da coleta. Jatúlika e Niwatima fica com a mãe e a avó na oca. Há um choque de idéias, perspectivas, sonhos entre os mais velhos e os dois jovens. Jatúlika parece viver os dois mundos do índio e do não-índio, ele sonha em ser caminhoneiro ou soldado da polícia militar, mas ao mesmo tempo adora ir caçar com o pai que prefere não levá-lo por dizer que ele faz muito barulho. Niwatima quer muito se casar com um Tapirapé, mas não pensa em deixar a família para morar na Ilha do Bananal.
} 
Os Avá-Canoeiros vivem em um território permeado por atores e interesses de várias ordens que estão no Cerrado do norte goiano. Na Terra Indígena Avá-Canoeiro os principais atores que marcam as disputas e conseqüentemente os conflitos são: A Usina Hidrelétrica de Serra da Mesa representando o hidronegócio ${ }^{14}$ na região que "invadiu" parte do território indígena e o controle da FUNAI na reserva (aos Avá-Canoeiro) e na busca dos direitos por essa “invasão".

Essas questões políticas e econômicas entre Furnas e FUNAI estão inseridas no Território e são ausentes na vida dos Avá-Canoeiro. Para grande parte dos povos indígenas a terra é sagrada; nela viveram seus ancestrais e habitam suas tradições, por isso representa também seus sentimentos e não disputas e conflitos.

Dessa forma, os contextos vividos pelos Avá-Canoeiro, é justamente sua história no e com o lugar que refletirá as marcas e pistas que dizem sobre este grupo. Além do seu sentido de uso, os lugares representam as significações de sua existência, os lugares se relacionam e estão vivos - na imaginação- no subconsciente- nos traumas- nas lembranças de cada Avá-Canoeiro.

É no lugar, no cotidiano da vida dos Avá-Canoeiro, que se estabelece um conjunto de relações para a produção da vida, envolvendo o ato de morar, trabalhar, caçar, comer, caminhar, os objetos, a natureza e são essas relações que envolvem a cultura desse povo.

Sabe-se que o território goiano foi e está sendo ocupado de maneiras desiguais, heterogêneas e em tempos distintos. $O$ sul e sudoeste goiano são dominados pelas atividades agroindustriais calcadas, sobretudo no agronegócio, as paisagens se resumem em grandes plantações de soja, milho, algodão, sorgo, cana-de-açúcar, entre outras. Enquanto que o norte ainda não foi "invadido" pelo agronegócio, mas e pressionado pelo hidronegócio devido à grande potencialidade do rio Tocantins.

Em suma, Goiás é um território múltiplo com territorialidades sobrepostas, formando um mosaico territorial. Esse fato explica a importância dos Avá-Canoeiro para o Cerrado do norte goiano, como protetores e guardiões e também como uma

\footnotetext{
${ }^{14} \mathrm{O}$ processo de apropriação da base material da vida, que é a água, e da sua incorporação ao processo de acumulação de capital.
} 
cultura viva depois dos inúmeros massacres. Os Avá-Canoeiro são símbolos da resistência.

\section{Biodiversidade do Cerrado: Algumas Considerações}

No Brasil, o termo biodiversidade no senso comum normalmente é associado à Amazônia, região que detém uma das mais vastas coleções de espécies animais e vegetais do mundo. Ocorre, porém, que o país conta com outros biomas importantes, como é o caso do Cerrado, cujos recursos naturais também são diversificados. O Cerrado é considerado um dos hotspots de biodiversidade no mundo (MYERS et al, 2000), ou seja, uma das zonas de grande diversidade biológica, considerando seus aspectos naturais.

Em extensão o Cerrado é o segundo ecossistema brasileiro, abarca uma área de 2.039.387 km², abrangendo 11 estados e o Distrito Federal (IBGE, 2004), fazendo uma interconexão com os outros biomas brasileiros como: Caatinga, Mata Atlântica, Amazônia, Pantanal, Matas de Araucárias.

Sua distribuição inclui as nascentes e parte considerável das três maiores bacias da América do Sul (Paraguai - Paraná, Araguaia-Tocantins e São Francisco, além do Aqüífero Guarani um dos maiores reservatórios de água subterrânea do mundo).

O Cerrado é determinado principalmente por variações topográficas regionais e formas de relevo, por limitações hídricas e edáficas (MOTTA, CURI, FRANZMEIER, 2002) e pela sazonalidade pluviométrica, em que mais de $80 \%$ da precipitação anual se concentra entre outubro e abril (CASTRO, et al., 1994).

É por meio da proteção desse bioma que se pode assegurar um maior volume e a melhoria da qualidade das águas, condições que hoje, se encontram ausentes em grande parte de nossos mananciais. $\mathrm{O}$ que se procura definir com o termo Cerrado não é apenas um tipo vegetação, mas um conjunto de tipos fisionomicamente distribuídos dentro de 
um gradiente distinto que temos como limites, de um lado o campo limpo ${ }^{15}$ e de outro lado o Cerradão ${ }^{16}$.

A presença de variados ambientes é que atribui, ao Cerrado, o caráter fundamental da biodiversidade. Compreender a distribuição dos elementos da flora e fauna pelos diversos subsistemas e seu ciclo anual é muito importante para uma visão de globalidade, que caracteriza considerar o Cerrado como ambiente produtivo, destinado também aos usos do capital.

O Cerrado é extremamente rico em fauna, flora, muitas espécies de animais e plantas ainda não são conhecidas ou não foram catalogadas. No que se refere a frutíferas, o Cerrado se apresenta como um dos mais ricos; oferecendo uma grande quantidade de frutos comestíveis, alguns de excelente qualidade, cujo aproveitamento por populações humanas, ocorre desde os primórdios da ocupação e, em épocas atuais muitos são aproveitados também de forma artesanal.

São exemplos de frutos do Cerrado: Açaí - Ata (Pinha) - Cagaita - Cajazinho Cupuaçu - Araticum - Mangaba - Caju - Pequi - Jenipapo - Jatobá - Guapeva- Araçá Ingá, entre outras. A figura 05 mostra alguns frutos do Cerrado, que são bastante consumidos.

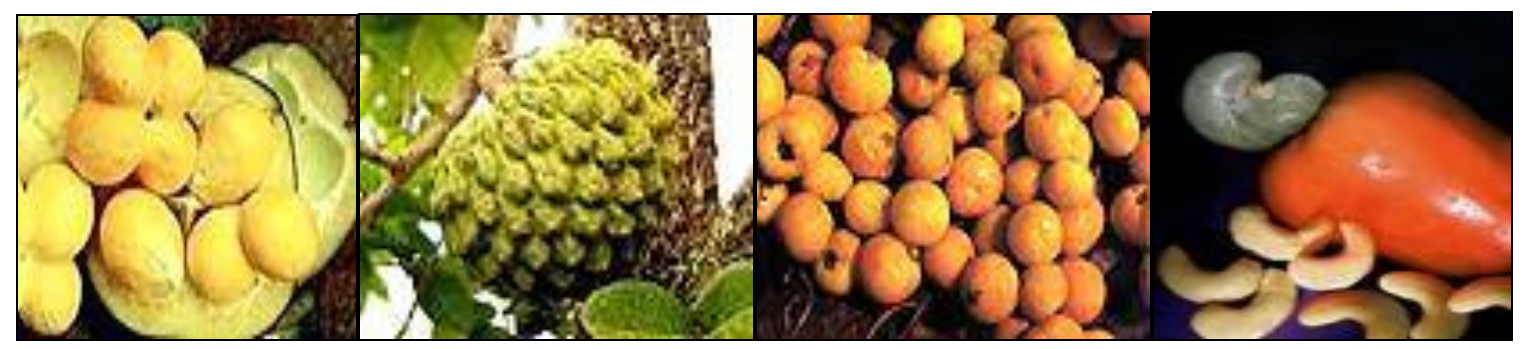

Figura 05: Frutos do Cerrado - da esquerda para a direita: Pequi, Araticum, Cagaita e Caju Organização: SILVA, Lorranne Gomes da. Fonte: www.portalbrasil

Encontra-se no Cerrado: canela-de ema, algodão, agoniada, sangra d'água, pé de perdiz, aroeira, romã, cravim do campo, lixeirinha, buchinha, velame branco ${ }^{17}$ entre outros. Alguns desses recursos, frutíferos ou não, constituem potenciais fontes de

\footnotetext{
${ }^{15}$ Constitui-se de vegetação herbácea, densa, composta de gramíneas e, alguns arbustos.

Tais campos são encontrados nas encostas, nas áreas de chapadas e nas proximidades das nascentes de água, circundando as bordas de matas galeria.

${ }^{16}$ É uma vegetação de caráter florestal, com árvores mais desenvolvidas que a dos demais tipos fitofisionômicos. Graças aos solos mais profundos e úmidos ele, também, apresenta algumas camadas de folhas em decomposição.
} 
exploração econômica de certa grandeza, cuja pesquisa e o desenvolvimento de tecnologias viabilizam seu aproveitamento em curto prazo $^{18}$.

A fauna do Bioma do Cerrado é pouco conhecida, particularmente a dos invertebrados. Seguramente ela é muito rica, destacando-se o grupo dos Insetos. Quanto aos vertebrados, o que se conhece são, em geral, listas das espécies mais freqüentemente encontradas em áreas de Cerrado, pouco se sabendo da história natural desses animais, do tamanho de suas populações, de sua dinâmica etc.

Entre os vertebrados de maior porte encontrados em áreas de Cerrado, citamos a jibóia, a cascavel, várias espécies de jararaca, o lagarto teiú, a ema, a seriema, a curicaca, o urubu comum, o urubu caçador, o urubu-rei, araras, tucanos, papagaios, gaviões, o tatu-peba, o tatu-galinha, o tatu-canastra, o tatu-de-rabo-mole, o tamanduábandeira e o tamanduá-mirim, o veado campeiro, o cateto, a anta, o cachorro-do-mato, o cachorro-vinagre, o lobo-guará, a jaritataca, o gato mourisco, e muito raramente a onçaparda e a onça-pintada.

A figura 06 mostra algumas espécies de animais do Cerrado:

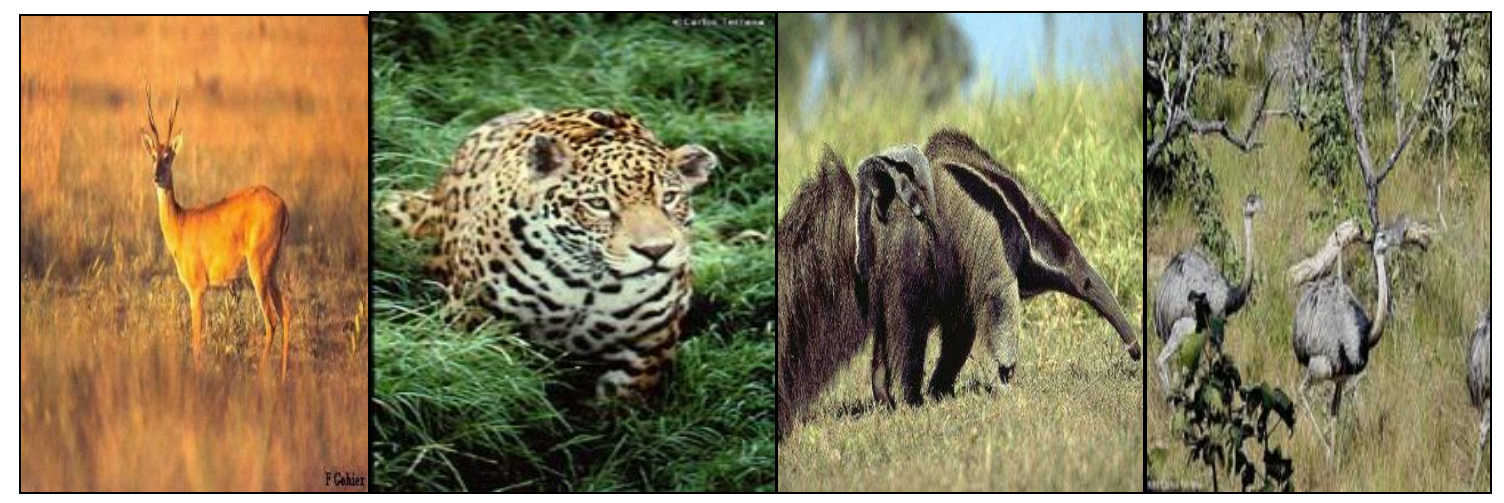

Figura 06: Animais do Cerrado - da esquerda para a direita: Veado campeiro; onça pintada;tamanduábandeira e ema.

Organização: SILVA, Lorranne Gomes da. Fonte: http://www.megadiversidade.com.br

\footnotetext{
${ }^{17}$ São nomes populares.

${ }^{18}$ Como é o caso do baru que vem sendo inserido no lanche de algumas escolas do norte goiano. O fruto (baru) é um legume lenhoso, castanho com uma única amêndoa comestível, que amadurece de setembro a outubro. É nativo da vegetação do Cerrado brasileiro e das faixas de transição da Mata Atlântica para o cerrado (na floresta latifoliada semidecidual). Ocorre nos estados de Minas Gerais (Triângulo Mineiro), São Paulo (norte do estado), Mato Grosso, Mato Grosso do Sul e Goiás. (Fonte: Wikipédia, a enciclopédia livre- http://pt.wikipedia.org/wiki/Baru) - Acesso: dia 21/02/2010.
} 
As espécies, insetívoras encontram de setembro a janeiro proporcionando a revoada e a multiplicação de certas espécies. Alguns répteis como a iguana, tracajá, calango e a perereca são bastante encontrados. Entre as espécies de peixes estão: tucunaré, abotoado, piranha-preta, corvina, cascudo, cachorra, etc.

A maior parte das aves põe seus ovos durante a estação seca, mais especificamente em junho, julho e agosto. As aves campestres estão mais concentradas no início da estação chuvosa. São exemplos de aves do Cerrado: Canindé, gavião carrapateiro, tucano, periquito estrela, papagaio galego, jacu, entre outros.

O Cerrado é exuberante, mas nas últimas três décadas a agricultura moderna vem se expandindo, de forma acelerada, reestruturando o espaço agrário desse bioma em vários aspectos (sociais, culturais, econômicas, ambientais), provocados pela incorporação do meio técnico-científico e informacional nas relações de produção, transformando-o na principal fronteira de expansão agrícola brasileira e uma das áreas mais ameaçadas pela intervenção humana. Almeida (2002, p.40), afirma que:

\begin{abstract}
A natureza se reinventa na modernidade pelo seu valor. Florestas, matas, manguezais, cerrado e caatinga suscitaram valorizações diversas e até contraditórias na exploração, preservação e conservação. É claro que o valor atribuído a estes lugares está vinculado à consciência que os homens têm de sua relação à natureza: de recurso, principalmente econômico, domesticada, espetáculo e/ou exibição e inesgotável; ao contrário, nesta relação ela pode ser ainda, empecilho, selvagem e perecível.
\end{abstract}

Nesse sentido para Almeida, a natureza passa ser medida - e essa medida tem valores econômicos. O fato é que a velocidade do uso, o modo como é usada e as intenções para qual servem o uso da biodiversidade do Cerrado são objetos que devem ser investigados.

Preservar o Cerrado é garantir a vida em equilíbrio das espécies. A destruição de algumas espécies pode provocar o aumento populacional de outras, gerando, assim, desequilíbrios com consequiências danosas a todos que habitam um determinado local. De acordo com Albagli (1998, p. 63):

A biodiversidade não consiste, portanto, tão-somente em um conjunto somatório de seres vivos, mas em um sistema cujos componentes mantêm relações de interdependência e de complementaridade, e cujo equilíbrio das partes afeta do todo e vice-versa. 
Em suma, o Cerrado além de apresentar uma vasta biodiversidade abriga grande parte da população, agregando uma pluralidade de costumes, valores e crenças. Por isso não é possível discutir a biodiversidade desconsiderando os sujeitos envolvidos. Para Almeida (2003, p. 75):

\begin{abstract}
A preservação das identidades e dos valores culturais, o enraizamento à terra aparecem como suportes da biodiversidade, da resiliência e da complexidade do ecossistema. São as populações que habitam as matas, cerrados e caatingas e as áreas rurais onde se expressa sua cultura ecológica, que têm condições de manter a base de recursos como legado de um patrimônio histórico e cultural.
\end{abstract}

Se os organismos vivos representam a somatória das riquezas da biodiversidade, os sujeitos são primordiais para compreender as modificações ocorridas nesses ambientes que conseqüentemente altera a vida.

No norte estão à maior parte da população quilombola a família Avá- Canoeiro sujeitos dessa pesquisa, além das áreas mais extensas de vegetação nativa.

Diante do exposto, o que representa os Avá- Canoeiro para a manutenção da biodiverdade do Cerrado do norte goiano?

\title{
Avá-Canoeiro: Guardiões do Cerrado do Norte Goiano
}

A Terra Indígena Avá-Canoeiro é uma importante área de preservação do Cerrado. Do ponto de vista jurídico os Avá-Canoeiro podem ser considerados como: "Guardiões do Cerrado do norte goiano". Tem o direito pela posse da terra e contam com as prerrogativas legais da lei federal 6.001/73.

A proteção constitucional do indígena tem seu início com a Constituição Federal de 1934 no seu artigo 129, onde desde já legitima o direito à posse das terras por eles ocupadas permanentemente, e veda a alienação. De acordo com o Art. 129 - "Será respeitada a posse de terras de silvícolas que nelas se achem permanentemente localizados, sendo-lhes, no entanto, vedado aliená-las".

A Constituição Federal de 1988 define que as terras indígenas, apesar de serem bens da União, são de posse permanente dos índios, bem como o usufruto exclusivo das riquezas do solo, dos rios e dos lagos nelas existentes. Com relação à conservação ambiental, as terras indígenas, apesar de não serem consideradas Unidades de Conservação (UC) pelo Sistema Nacional de Unidades de Conservação da Natureza - 
SNUC são de extrema importância. Algumas estão sendo incluídas e utilizadas como corredores ecológicos por causa de sua localização, abrangência e quantidade como é o caso da Terra Indígena Avá-Canoeiro.

Os Avá-Canoeiro ao garantirem esse território para a etnia estão de certa forma mantendo a biodiversidade da reserva, já que o pequeno número de pessoas não alteram as formas de uso e manejo. Dessa forma, são "Guardiões do Cerrado" por dois fatores: jurídico e cultural.

A figura 07 mostra as variadas fitofissionomias presentes na reserva indígena, ressaltando a importância dessa paisagem, já que em grande parte do Cerrado é possível ver apenas fragmentos dessas fitofissionomias.

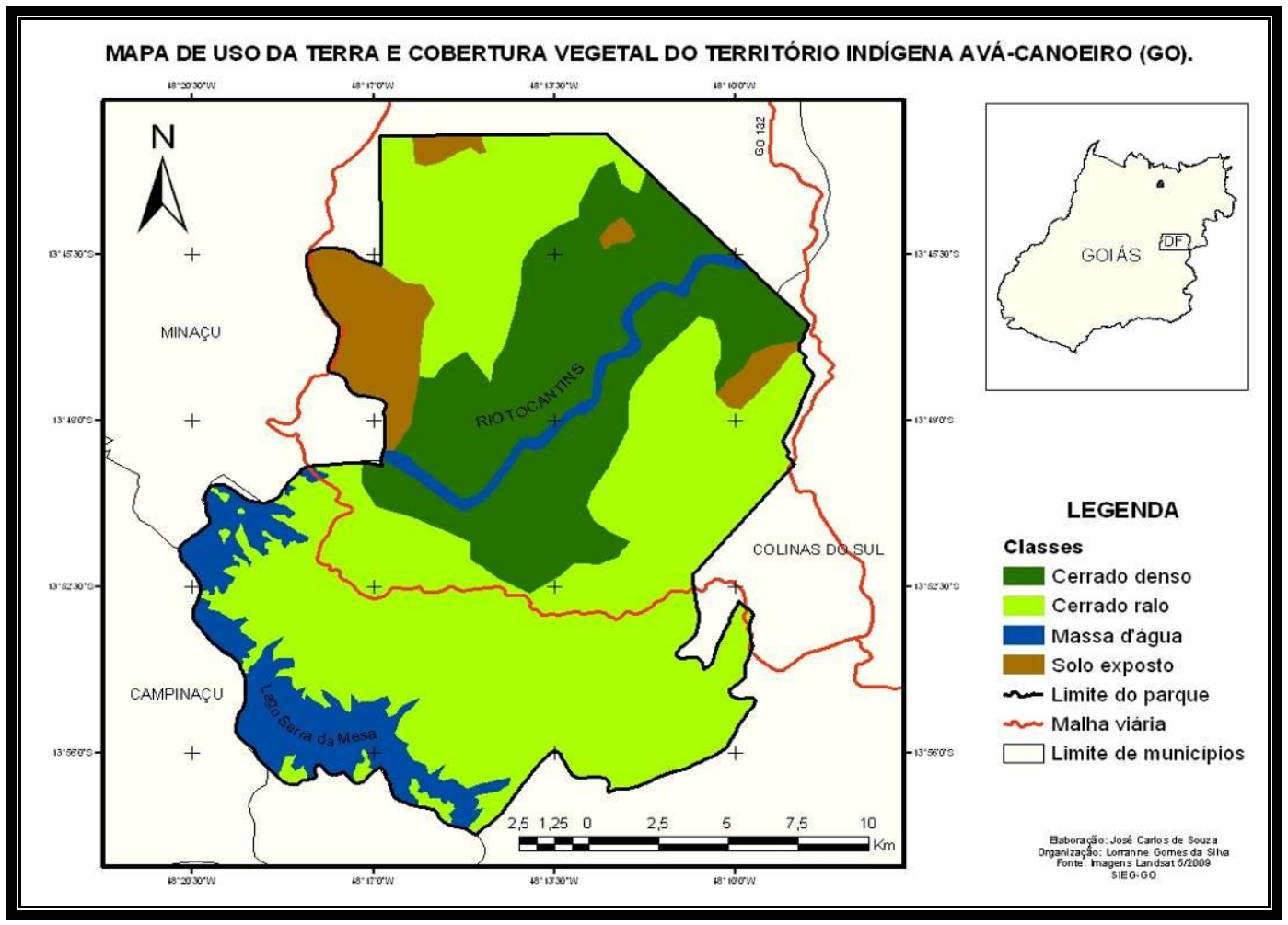

Figura 07: Uso da Terra e cobertura vegetal do Território Indígena Avá-Canoeiro

De acordo com o mapa as principais categorias fitofisionômicas encontradas na reserva são a mata de galeria, notadamente às margens do rio Tocantins e nos fundos dos vales; a mata mesofítica, o cerrado típico, o campo cerrado e capoeiras, e constitui uma das últimas fronteiras do cerrado norte goiano. Estas distinções estão relacionadas 
principalmente, às diferenças pedológicas, geomorfológicas, climatológicas e topográficas (RIBEIRO; MONTEIRO, 1998).

Em decorrência do relevo ondulado e solos considerados pobres em nutrientes, essa porção do norte goiano não despertou tanto a cobiça das frentes de expansão agropastoris, preservando assim, extensas áreas relativamente intactas da natureza. Abriga quase todos os exemplares da fauna típica do cerrado, a exemplo de lobos guará, tatus, tamanduás, cotias, pacas, antas, capivaras, quatis, várias espécies de pássaros e cobras.

Registra-se também na reserva uma ampla variação botânica ${ }^{19}$ que vai desde árvores frutíferas, plantas medicinais a árvores madeireiras (madeira de lei) $\operatorname{como}^{20}$ : Lixeira, pau-terra, pequi, pau-de-santo, barbatimão, quimera branca, murici, mangaba, puçá, tucum, xixá, jatobá, pinhão, buriti, graviola, jatobá, tamboril, tarumã, aroeira, angico, buriti, Alfafava, cagaita, orelha de moça, pinhão, açaí - cajazinho - cupuaçu araticum, caju - pequi, jenipapo - Jatobá - guapeva- Araçá, ingá, entre outras.

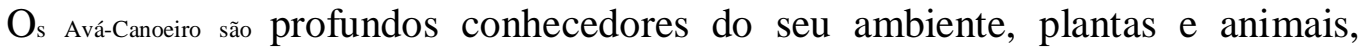
nomeando as várias espécies. Eles associam as estações do ano e as fases da Lua com o clima, a fauna e a flora da região em que vivem. Para eles, cada elemento da Natureza tem um espírito protetor. Matxa em uma de suas narrativas contou que as ervas medicinais eram preparadas obedecendo a um calendário anual bem rigoroso.

Em virtude da longa prática de observação da lua, os Avá-Canoeiro conhecem e utilizam suas fases na caça, no plantio e no corte da madeira. Eles consideram que a melhor época para essas atividades é entre a lua cheia e a lua nova (lua minguante), pois entre a lua nova e a lua cheia (lua crescente) os animais se tornam mais agitados devido ao aumento de luminosidade.

Atualmente, há um grande interesse internacional na proteção e conservação do conhecimento tradicional e de práticas ancestrais de indígenas e das comunidades locais, para a conservação da biodiversidade.

Os Avá-Canoeiro utilizam o Cerrado como componente para sua sobrevivência; realizando a coleta de frutos, caça, pesca, coleta de ervas medicinais, coleta de madeira,

\footnotetext{
${ }^{19}$ Esses dados foram coletados durante o trabalho de campo na entrevista com Walter Sanches, chefe de posto da funai, responsável pela reserva e pelos Avá-Canoeiro, segundo Walter não existe esses dados publicados ainda.

${ }^{20}$ Walter ressaltou que são nomes populares, nunca fizeram um estudo científico na reserva.
} 
folhas de algumas espécies como buriti, para cobrirem sua oca, estando esses componentes inteiramente ligados aos diferentes locais nos quais moldam a trajetória desse povo. Os lugares são fonte de conhecimento e novas táticas de vida, como mostra a figura 08:

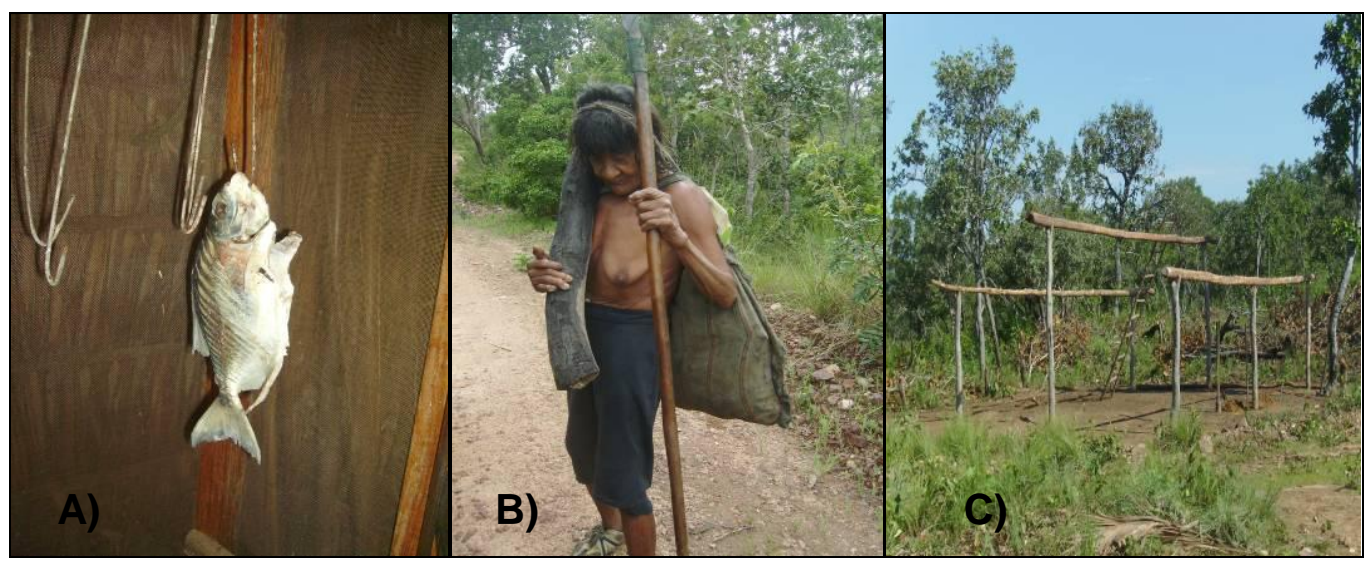

Figura 08: (A) Peixe pescado por Iawi com lança; (B) Nakwatxa coletando lenha para o almoço e milho da roça; (C) Construção de uma nova oca com madeira de aroeira Autora: SILVA, Lorranne Gomes da

No caso da biodiversidade do Cerrado, os Avá-Canoeiro integra a natureza ao seu próprio sistema cultural, em uma relação de muito respeito. Conhecem várias espécies, mas tem suas preferências para caça e coleta. Não estocam grandes quantidades não havendo perdas dos alimentos coletados. A utilização dos recursos naturais para a garantia de sua sobrevivência e as práticas são sustentáveis.

Sabe-se que essa família corre um grande risco de extinção devido ao diminuto número populacional. O questionamento que fica é o que acontecerá com esse território no futuro - com a ausência dos Avá-Canoeiro?

\section{Considerações Finais}

Almeida (2003, p.71), afirma que: "O discurso sobre a biodiversidade situa-se nas formas pós-modernas do capital com (re) significações das florestas tropicais, suas populações tradicionais e seus conhecimentos da natureza". O conhecimento tradicional pode ser considerado nesse âmbito, como a forma mais antiga de produção de teorias, experiências, regras e conceitos, isto é, a mais ancestral forma de produzir ciência. 
O que faz um grupo social ser identificado como tradicional não é a localidade, mas seu modo de vida, suas formas de estreitar relações com a diversidade biológica, em função de uma dependência que não precisa ser apenas com fins de subsistência, pode ser também material, econômica, cultural, religiosa, espiritual, etc.

Os povos indígenas do Cerrado goiano apresentam conhecimentos tradicionais (saberes) e modalidades de uso de espécies do bioma que não comprometem a sua redução, tal como tem sido as atividades econômicas capitalistas, tanto da agricultura moderna como da indústria.

No caso específico dos Avá-Canoeiro, além de sua cultura ecológica não ser a da acumulação, a vastidão de sua terra, contrastando com a sua diminuta população, são fatores de preservação da biodiversidade que infelizmente nunca foi estudada, muito menos catalogada por nenhum órgão.

Em verdade, se tornam também "Guardiões do Cerrado" pelo fato de serem poucos e usarem o mínimo dos recursos da natureza e porque atualmente não realizam quase nada de seus costumes e tradições. Não fazem mais nenhum tipo de artesanato, são desestimulados a caça, pesca e coleta já que a FUNAI oferece uma cesta básica mensal, as músicas desapareceram, as pinturas plumárias e de qualquer outro tipo também.

Em suma, o norte goiano não sofreu, por diversas razões, o nível de exploração de outras regiões do Estado de Goiás. Esse fator explica os 38.000 hectares destinados à família Avá-Canoeiro que no sudoeste goiano dificilmente teriam essa área, já que os investidores aproveitam todas as terras cultiváveis para a intensa produção de grãos.

Assim, os dois fatores - o da cultura ecológica dos Avá-Canoeiro junto com a posição do norte - são elementos que protegem a biodiversidade, mas, não acabam com outros níveis de pressão, como é a participação do hidronegócio e de atividades mineroextrativistas.

\section{Referências Bibliográficas}

ALMEIDA, M. G. Capacitando para a cidadania: Turismo e qualidade de vida nos municípios do entorno do Lago da UHE Serra da Mesa - Goiás. Goiânia, 2002. (Projeto de Pesquisa - Proposto a FUNAPE - UFG) (Impresso) 
.Cultura Ecológica e Biodiversidade. Mercator- Revista de Geografia da UFC, Fortaleza, ano 2, n. 03, p. 71-82, 2003.

ALBAGLI, Sarita. Geopolítica da biodiversidade. Brasília: Instituto do Meio Ambiente e dos Recursos Naturais Renováveis, 1998.

BARBOSA, Altair Sales. Ocupação Indígena no Sistema Biogeográfico do Cerrado. In: GOMES, Horieste (Coord.). Universo do Cerrado. Goiânia: Ed. UCG, 2008. (Vol. 1).

BORGES, Mônica Veloso. O estudo do Avá: relato e reflexões sobre a análise de uma língua ameaçada de extinção. Rev. Liames, Campinas: Unicamp, n. 2, p. 85-104, 2002.

CASTRO, L.H.R., Moreira, A.M.; ASSAD, E.D. Definindo padrões espaciais de precipitação no Cerrado Brasileiro. In: Chuvas nos Cerrados: Análise e Espacialização, Brasília, DF: Embrapa-SPI, 1994.

FUNAI. Fundação Nacional do Índio. Índios do Brasil. As Terras Indígenas. Mapa de etnias. Brasília: FUNAI, 2004. Disponível em htt: www.funai.gov.br/índios/terras/conteúdo.htm. Acesso em: 25 set. 2009.

IBGE. Mapas interativos (Mapa de Biomas), 2004. URL http://www.ibge.gov.br/mapas/. Acesso em: 20 out. 2009

MYERS, N. et all. Biodiversity hotspots for conservation priorities. Nature, n. 403, p. 853-858, 2000.

MOTTA, P.E.F., CURI, N.; FRANZMEIER, D.P. Relation of soils and geomorphologic surfaces in the Brazilian Cerrado. In: OLIVEIRA, P. S; MARQUIS, R.J. (Eds).The Cerrados of Brazil: ecology and natural history of a Neotropical savanna. Columbia, NY: University Press. 2002. p. 13-32

MOURA, Marlene Castro Ossami de. (coord). Índios de Goiás: uma perspectiva Histórico-Cultural. Goiânia: Ed. da UCG/Ed. Vieira/Ed Kelps, 2006.

TEIXEIRA NETO, Antônio. O Território Goiano: Formação e Processo de povoamento e urbanização. In: ALMEIDA, Maria Geralda. Abordagens Geográficas de Goiás: o natural e o social na contemporaneidade. Goiânia: IESA, 2002.

RIBEIRO, J. F e MONTEIRO. M. T. Fitofissionomias do Bioma Cerrado. In: SANO, S.M e ALMEIDA, S.P. Cerrado: Ambiente e flora. Planaltina, Embrapa/CPAC, 1998.p.89-166.

RIVET, Paul. Les indiens Canoeiro. Journal de la Société des Américanistes. Paris: Société des Américanistes. Revista. V. 16, 1924. 
SILVA, Cristian Teófilo. Cativando Maira - A sobrevivência Ava-Canoeiro no Alto Rio Tocantins. 2005. Tese (Doutorado em Antropologia) - UNB. Brasília. 2005.

TORAL, André Amaral. "Os índios negros ou os Carijó de Goiás: a história dos AváCanoeiro". Revista de Antropologia. São Paulo: USP, v. 17 e 18, p. 287-325, $1984 / 1985$.

\section{SITES CONSULTADOS}

http://www.megadiversidade.com.br. Acesso em: 11 jan. 2009.

http://www.portalbrasil - Acesso em: 20 dez. 2009.

http://pt.wikipedia.org/wiki/Baru) - Acesso em: 10 fev. 2010.

http://www.planalto.gov.br/ccivil_03/constituicao/constitui\%C3\%A7ao.htm-

Constituição da República Federativa do Brasil de 1988. Acesso em: 01 mar. 2010.

http://www.planalto.gov.br/ccivil_03/constituicao/constitui\%C3\%A7ao.htm.Acesso em: 01 mar. 2010.

Recebido para publicação em fevereiro de 2010 Aprovado para publicação em março de 2010 